\title{
Molecular Dynamics Simulations of the Tensile Mechanical Responses of Selective Laser-Melted Aluminum with Different Crystalline Forms
}

\author{
Qiang Zeng ${ }^{1}$, Lijuan Wang ${ }^{1, *}$ and Wugui Jiang ${ }^{2, *}$ (D) \\ 1 School of Mechatronics Engineering, Nanchang University, Nanchang 330031, China; \\ zengqiang96@email.ncu.edu.cn \\ 2 School of Aeronautical Manufacturing Engineering, Nanchang Hangkong University, \\ Nanchang 330063, China \\ * Correspondence: wlj@ncu.edu.cn (L.W.); jiangwugui@nchu.edu.cn (W.J.)
}

Citation: Zeng, Q.; Wang, L.; Jiang, W. Molecular Dynamics Simulations of the Tensile Mechanical Responses of Selective Laser-Melted Aluminum with Different Crystalline Forms. Crystals 2021, 11, 1388. https://doi.org/10.3390/cryst11111388

Academic Editors: Koichi Kakimoto and Tomasz Sadowski

Received: 16 September 2021 Accepted: 10 November 2021 Published: 14 November 2021

Publisher's Note: MDPI stays neutral with regard to jurisdictional claims in published maps and institutional affiliations.

Copyright: (C) 2021 by the authors Licensee MDPI, Basel, Switzerland. This article is an open access article distributed under the terms and conditions of the Creative Commons Attribution (CC BY) license (https:// creativecommons.org/licenses/by/ $4.0 /)$

\begin{abstract}
The mechanical deformation of cellular structures in the selective laser melting (SLM) of aluminum was investigated by performing a series of molecular dynamics (MD) simulations of uniaxial tension tests. The effects of crystalline form, temperature, and grain orientation of columnar grains on the mechanical properties of SLM aluminum were examined. The MD results showed that the tensile strength of SLM aluminum with columnar grains at different temperatures was lower than that of single-crystal aluminum, but greater than that of aluminum with equiaxed grains. The tensile strength and Young's modulus both decreased approximately linearly upon increasing the temperature. The deformation mechanisms of equiaxed and columnar grains included dislocation slip, grain boundary migration, and torsion, while the deformation mechanisms of single crystals included stacking fault formation and amorphization. Finally, the influence of the columnar grain orientation on the mechanical properties was studied, and it was found that the Young's modulus was almost independent of the grain orientation. The tensile strength was greatly affected by the columnar grain orientation. Reasonable control of the grain orientation can improve the tensile strength of SLM aluminum.
\end{abstract}

Keywords: selective laser melting; aluminum; crystalline state; grain orientation; molecular dynamics

\section{Introduction}

Additive manufacturing (AM) is a rapidly developing technology based on computer assistance and material accumulation that can reduce manufacturing costs of low-volume products and processing times compared with conventional manufacturing techniques [1]. Selective laser melting (SLM) is a laser-based AM technology that has been widely used to manufacture key components in the automotive, medical equipment, aerospace, and mold manufacturing fields $[2,3]$.

In recent years, aluminum has been widely used in the manufacturing industry owing to its excellent corrosion resistance and high thermal conductivity. However, traditional preparation methods of aluminum components with complex shapes require long preparation cycles and produce material waste. Selective laser melting can reduce material usage, shorten the forming cycle, and prepare complex-shaped parts; thus, the application of aluminum in SLM has also increased, and some scholars have conducted related experimental research on the mechanical properties of SLM-processed aluminum [4-11]. Li et al. [6] conducted tensile tests on a solution heat-treated SLM AlSi10Mg alloy and found that the ultimate strength and ductility both decreased upon increasing the solution temperature. Takata et al. [7] found that an SLM AlSi10Mg alloy exhibited a unique microstructure that increased its strength. Many studies have also reported the existence of fine and complex microstructures in aluminum parts manufactured by SLM [8-11]. Ben et al. [10] 
reported that an SLM AlSi10Mg alloy had a multi-level heterogeneous microstructure composed of melt pools, columnar grains, and sub-cells. Chen et al. [11] used EBSD to analyze the microstructure of the SLM AlSi10Mg alloy and show the different grain orientation distributions. The unique microstructure of AlSi10Mg has not been observed in other SLM-fabricated materials, except for metallic alloys such as 316L SS, Al12Si, and CoCrMo [12].

Although relevant studies have shown that this special microstructure can improve the mechanical properties of a material, there is no in-depth and systematic understanding of the microstructure evolution and changes in mechanical properties during the forming process of SLM aluminum. Because experimental investigations are costly or nearly impossible, molecular dynamics (MD) simulations have been widely used to study the evolution of atomic structures and mechanical properties. We note that recent works employed ab initio MD to investigate the mechanical properties of materials subject to tensile deformation [13]. Although ab initio MD is more accurate than classical MD, the use of ab initio MD to model large systems that may include extended crystallographic defects is practically unfeasible. Kurian and Mirzaeifar [12] conducted MD simulations to study the deformation behavior of SLM 316L SS with columnar grains and found that under an applied strain, the primary plastic deformation mechanism was dislocation sliding. Ghaffarian et al. [14] conducted MD simulations to study the deformation behavior of polycrystalline cementite $\left(\mathrm{Fe}_{3} \mathrm{C}\right)$ and found that at low temperatures and large grain sizes, the main deformation mechanism was dislocation slip. When the temperature increased, the main deformation mechanism was grain boundary sliding. Husain et al. [15] used MD simulations to study the mechanical properties and plastic deformation mechanism of nanocrystalline 316L stainless steel with various average grain sizes. They found that as the temperature increased, the mechanical properties, such as the Young's modulus, ultimate strength, yield stress, and flow stress, decreased. Zepeda-Ruiz et al. [16] performed a serial of atomistic simulations to investigate the origins of metal hardening at its most fundamental level of atomic motion and they found that the notorious staged hardening of metals is a direct consequence of crystal rotation under uniaxial straining.

Recently, Branco et al. [17] used pure $\mathrm{Al}$ as the powder material for the SLM process, and they obtained nanocrystalline pure Al with grain sizes of $9.54 \mathrm{~nm}, 42.18 \mathrm{~nm}$, and $93.8 \mathrm{~nm}$ through a selective pulsed laser melting process. Many researchers have used MD simulations to study mechanical properties of nanocrystalline Al [18-20]. For example, Qi and Krajewski [18] performed MD simulations to study the effects of applied force and grain boundary misorientation on grain boundary sliding in aluminum at $750 \mathrm{~K}$. Yamakov et al. [19] clarified the complex interaction of nanocrystalline Al microstructure during plastic deformation at room temperature. In addition, they proved that mechanical twinning may play an important role in the deformation behavior of nanocrystalline aluminum compared with coarse-grained Al. Zhu et al. [21] conducted MD simulations to investigate the influence of inclined angles between the orientation of columnar grains and the loading direction on the mechanical properties of $\mathrm{FeCrNi}$ columnar polycrystalline samples by compression tests. However, there are few studies of the influence of the mutual orientation of columnar grains on the mechanical properties of cellular structures.

The purpose of this work was to use classical MD simulations to investigate the effect of the crystalline state, temperature, and grain orientation on the mechanical properties of SLM aluminum.

\section{Materials and Methods}

\subsection{Interatomic Potential}

MD simulates the motion between molecular systems by solving Newtonian equations of motion, where interaction forces are derived from the potential between atoms. Choosing accurate interatomic interaction potentials is very important in MD simulations; therefore, this study used the alloy potential in the embedded atomic potential (EAM) [22] to express $\mathrm{Al}-\mathrm{Al}$ interactions. The total potential energy expression of the system is as follows: 


$$
E=\sum_{i} F_{i}\left(\rho_{i}\right)+\frac{1}{2} \sum_{j \neq i} \varphi_{i j}\left(r_{i j}\right)
$$

where $F_{i}$ is the embedded energy of atom $i$ in background electron density $\rho_{i} ; \varphi_{i j}\left(r_{i j}\right)$ is a pairwise interaction, and $r_{i j}$ is the distance between atoms $i$ and $j . \rho_{i}$ can be expressed as:

$$
\rho_{i}=\sum_{j \neq i} f_{j}\left(r_{i j}\right)
$$

where $f_{j}\left(r_{i j}\right)$ is the background electron density of atom $j$ at the location of atom $i$.

MD simulations were performed with the Large-scale Atomic/Molecular Massively Parallel Simulator (LAMMPS) [23]. Periodic boundary conditions were applied in all directions. The energy was minimized by the conjugate gradient method to obtain a stable atomic configuration. To obtain the initial configuration, NPT (constant number of atoms, pressure, and temperature) was used to relax the system at $300 \mathrm{~K}-900 \mathrm{~K}$ and a pressure of 0 bar with a time step of $1 \mathrm{fs}$ for $80 \mathrm{ps}$. Owing to the limitations of MD timescale, the loading rate in the MD simulation is often much greater than the experimental loading rate. The author's group [24] and Wen et al. [25] reported that in the MD simulations of uniaxial tensile tests, the simulation results were not sensitive to the loading rate when the tensile strain rate was in the range from $1 \times 10^{8} / \mathrm{s}$ to $2 \times 10^{10} / \mathrm{s}$. Thus the "Deform" command was used to perform uniaxial tension simulations at $300 \mathrm{~K}-900 \mathrm{~K}$ under the NPT ensemble with a pressure of 0 bar at an engineering strain rate of $1 \times 10^{9} / \mathrm{s}$ for $300 \mathrm{ps}$. The temperature and pressure of the system were controlled by the Nosé-Hoover thermostat and a barostat [26]. The visualization software OVITO [27] was used to observe the atomic structure during the tensile process. A brief description of the computational configurations generated for studying the effect of the crystalline state and grain orientation is discussed in the following sections.

\subsection{Modeling Methods}

\subsubsection{Different Crystalline State Models}

To study the mechanical properties of aluminum in different crystalline states, singlecrystal, equiaxed, and columnar grain models were established, as shown in Figure 1. The ATOMSK [28] software and the Voronoi [29] construction method were used to construct the columnar and equiaxed models. The crystallographic directions [100], [010], and [001] lay along the $x-, y-$, and $z$-axes, respectively. The size of the single-crystal atom model was $60 a \times 60 a \times 10 a$, where the lattice constant $a$ of $\mathrm{Al}$ was $0.405 \mathrm{~nm}$, and the model was stretched along the $x$-axis, as shown in Figure 1a. The size of the equiaxed grain atom model was $33 a \times 33 a \times 33 a$, containing four randomly oriented grains. The model was stretched along the $x$-axis, and the average grain size was around $10.3 \mathrm{~nm}$, as shown in Figure $1 \mathrm{~b}$. The columnar atom model was modeled according to the TEM image observed by Ben et al. [10]. The size of the columnar grain atom model was $60 a \times 60 a \times 10 a$, and the number of grains was four; these were oriented through rotations about the $z$-axis [001] with angles of $0^{\circ}, 20^{\circ}, 40^{\circ}$, and $60^{\circ}$. The models were uniaxially stretched along the $x$ - or $z$-axes, respectively, so that lateral Poisson's contraction was allowed during elongation. The grain size of each grain was calculated as the diameter of a cylinder [30]. The average grain size was around $13.7 \mathrm{~nm}$, as shown in Figure 1c. The number of atoms in the single-crystal, equiaxed, and columnar grain models was 144,000, 143,749, and 144,000, respectively. The average grain size of the MD model in this work was about $12 \mathrm{~nm}$, which is within the range of the grain size experimentally obtained by Branco et al. [17]. In addition, owing to the limitations of the calculation scale of the traditional MD method, most of the current MD simulations for polycrystalline metals have grain sizes between $10 \mathrm{~nm}$ and $20 \mathrm{~nm}$ [24,31]. For example, Kurian and Mirzaeifar [12] modeled columnar grains with a grain size of $10.3 \mathrm{~nm}$ to $23.24 \mathrm{~nm}$ to study the deformation behavior of SLM 316 stainless steel, so the average grain size of the model in this work is reasonable. 
(a)

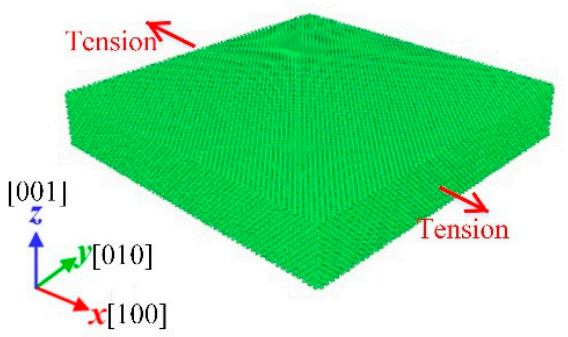

(c)

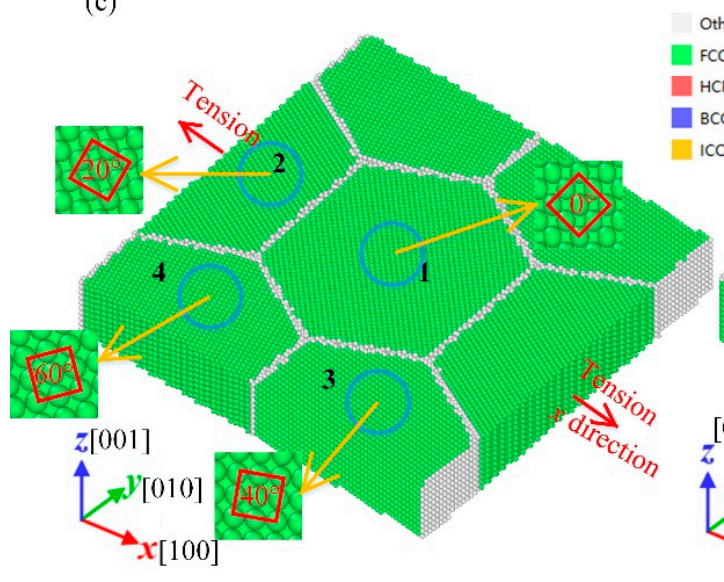

$\square$ FCC

(b)

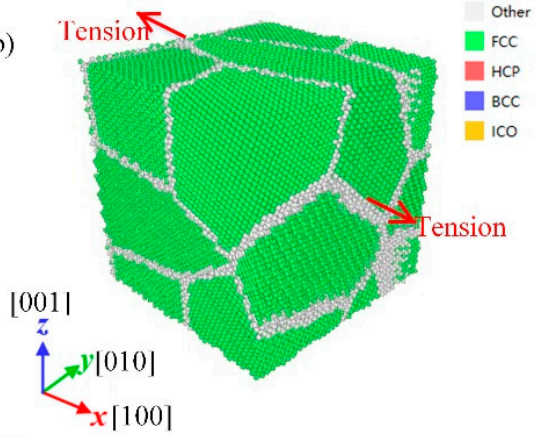

(d)

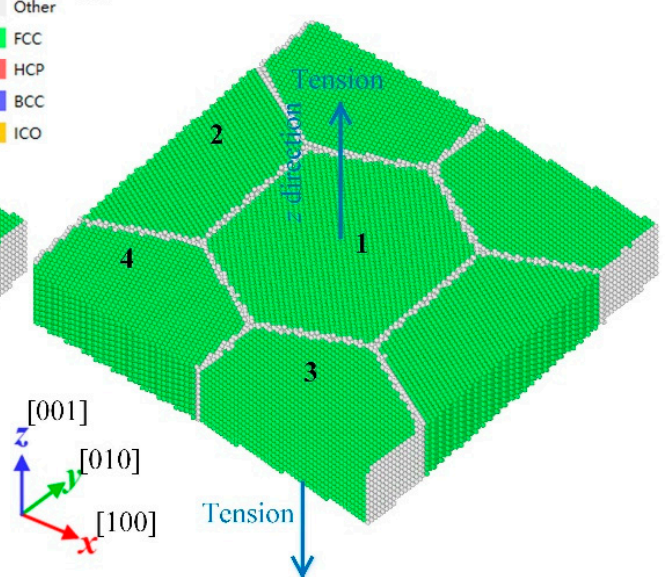

Figure 1. Different constructions of crystalline aluminum atom models: (a) single-crystal, (b) equiaxed grain, (c) $x$-direction tension, and (d) $z$-direction tension of columnar grains.

\subsubsection{Models of Columnar Grains with Different Grain Orientations}

A columnar atom model with grains rotated at different angles around the $z$-axis was established to investigate the influence of the columnar grain orientation on the mechanical properties. The model dimensions, tensile direction, and the number of grains were inherited from the model presented in Figure 1c. The crystal orientation was $x$-[100], $y$-[010], and $z$-[001], and a total of six different grain orientation models was established. The rotation angles of the grains around the $z$-axis were $(\mathrm{a})-5^{\circ}, 5^{\circ},-5^{\circ}, 5^{\circ},(\mathrm{b})-10^{\circ}, 10^{\circ}$, $-10^{\circ}, 10^{\circ}$, (c) $-15^{\circ}, 15^{\circ},-15^{\circ}, 15^{\circ}$, (d) $-20^{\circ}, 20^{\circ},-20^{\circ}, 20^{\circ}$, (e) $-25^{\circ}, 25^{\circ},-25^{\circ}, 25^{\circ}$, and (f) $0^{\circ}, 20^{\circ}, 40^{\circ}, 60^{\circ}$. The model is shown in Figure 2. The number of atoms was 144,000 , $143,840,144,080,144,000,144,000$, and 144,000, respectively. 

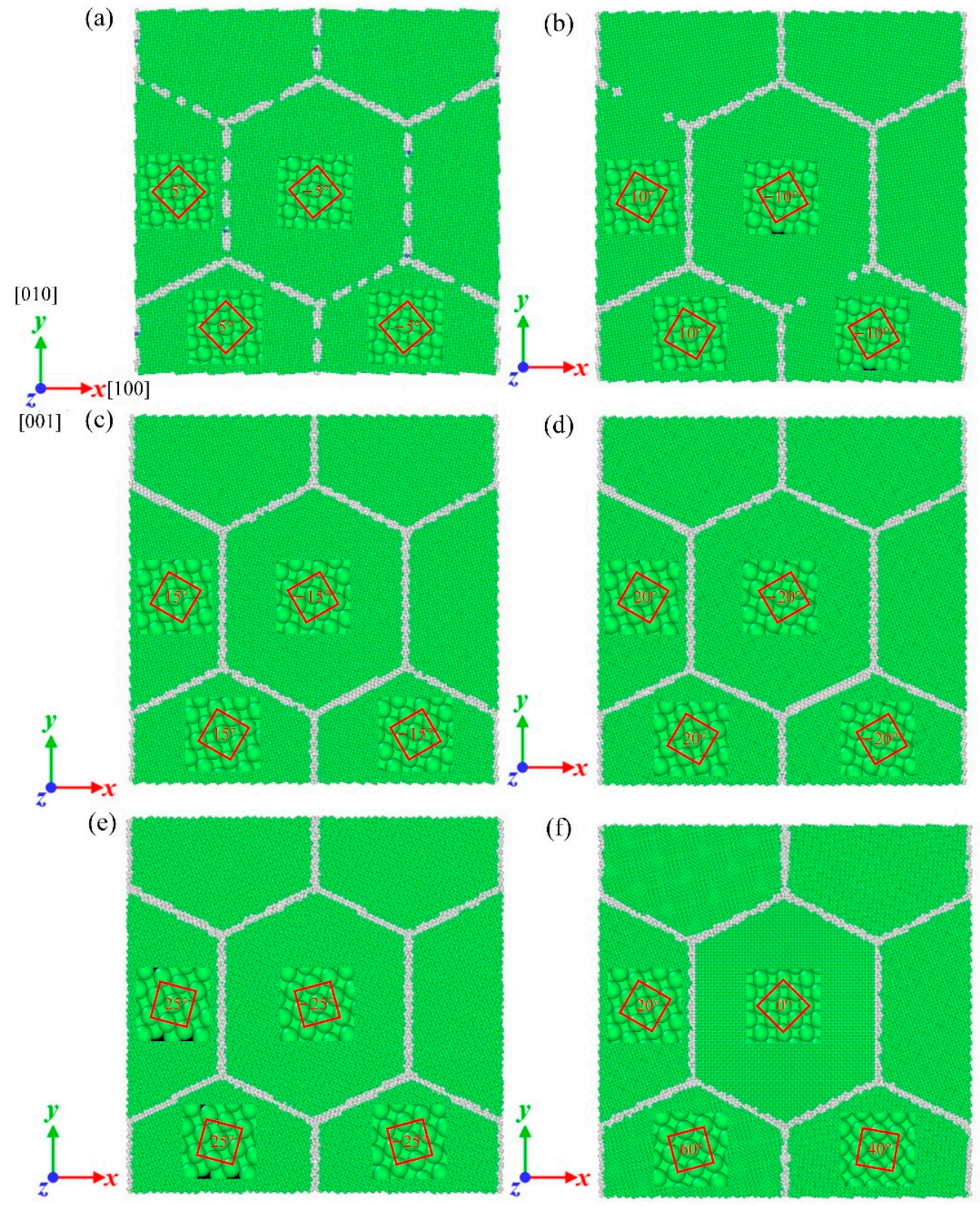

Figure 2. Atomic microstructure of grains with different orientations: (a) $-5^{\circ}, 5^{\circ},-5^{\circ}, 5^{\circ},(\mathbf{b})-10^{\circ}$, $10^{\circ},-10^{\circ}, 10^{\circ},(\mathbf{c})-15^{\circ}, 15^{\circ},-15^{\circ}, 15^{\circ},(\mathrm{d})-20^{\circ}, 20^{\circ},-20^{\circ}, 20^{\circ},(\mathbf{e})-25^{\circ}, 25^{\circ},-25^{\circ}, 25^{\circ},(\mathbf{f}) 0^{\circ}, 20^{\circ}$, $40^{\circ}, 60^{\circ}$.

\section{Results and Discussion}

3.1. Effect of Temperature on the Mechanical Properties of Aluminum with Different Crystal Structures

The temperature was set from $300 \mathrm{~K}$ to $900 \mathrm{~K}$ to perform tensile simulations of singlecrystal $\mathrm{Al}$, columnar grain $\mathrm{Al}$, and equiaxed grain $\mathrm{Al}$. Owing to the anisotropy of columnar grains, we also performed a tensile simulation along the $z$-direction for SLM columnar grains. The Young's modulus was determined by linear fitting of the strain data within $2 \%$ of the stress-strain curve. Figure 3 shows the stress-strain curves of aluminum with different crystal structures at $300 \mathrm{~K}$ and $900 \mathrm{~K}$, and Figure 4 shows the changes in Young's modulus and tensile strength of different crystal structures of aluminum at different temperatures. 

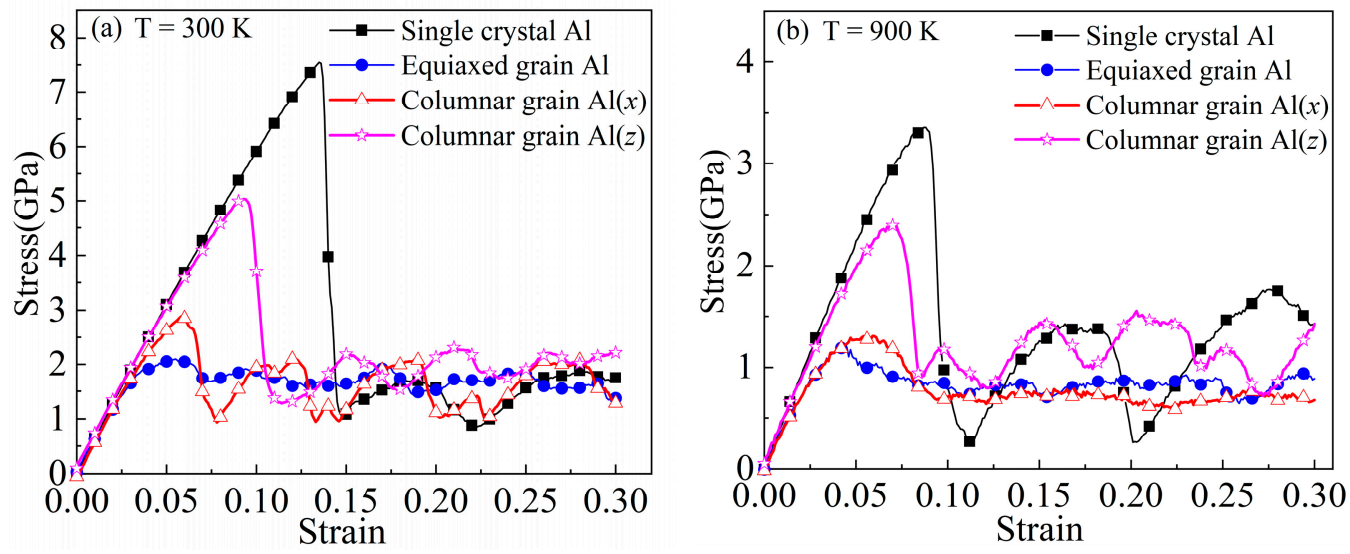

Figure 3. Stress-strain curves of aluminum with different crystal forms at: (a) $300 \mathrm{~K}$ and (b) $900 \mathrm{~K}$.
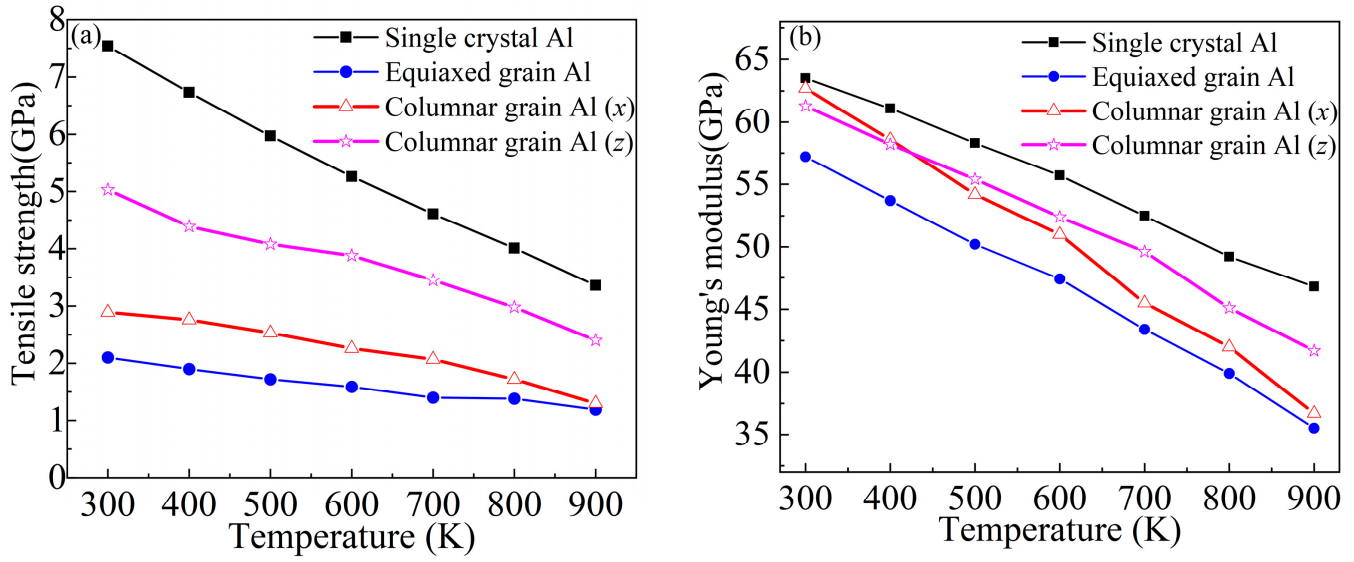

Figure 4. Tensile mechanical properties of aluminum with different crystal forms at different temperatures: (a) Tensile strength and (b) Young's modulus.

It can be seen from Figure 3 that the stress first increased with the applied tensile strain until it reached a maximum value, after which it dropped and then fluctuated around a mean value. This is basically consistent with a previous description in the literature [32]. The stress-strain curve of Figure 3 shows that the tensile strength of SLM aluminum with columnar grains at different temperatures was lower than that of single-crystal aluminum, but greater than that of aluminum with equiaxed grains. As the temperature increased, the Young's modulus, tensile strength, and yield strength decreased. The tensile strength of columnar grains stretched along the $z$-direction was much higher than those stretched along the $x$-direction. The Young's modulus in the $x$-direction calculated from our simulations was in the range of $61.3 \mathrm{GPa}$ to $63.5 \mathrm{GPa}$ for different crystalline crystal $\mathrm{Al}$, which is close to the MD-predicted value of $62.2 \mathrm{GPa}$ [33] and the experimental measurement value of $60.2 \mathrm{GPa}$ to $73 \mathrm{GPa}[34,35]$. The tensile strength of the columnar grains at room temperature predicted by our MD simulation was $2.431 \mathrm{Gpa}-4.017 \mathrm{GPa}$, which was consistent with the MD results of 2.5 Gpa-3.5 GPa reported by Zhang et al. [32]. We noticed that the tensile strength predicted by the MD simulations was much higher than the experimental value of $600 \mathrm{MPa}$ [34]. This is because the MD simulation w performed for a defect-free system at a loading rate much higher than the experimental value.

Figure 4a shows how the tensile strength changed with temperature. Upon increasing the temperature, the tensile strength decreased. The tensile strength of SLM aluminum with columnar grains was more sensitive to temperature than aluminum with equiaxed grains, but less sensitive than single-crystal aluminum. The tensile strength of the columnar grains stretched along the $z$-direction decreased faster than those stretched along the $x$-direction. The correlation between the tensile strength and temperature was approximately linear. 
Figure $4 \mathrm{~b}$ shows that as the temperature increased, the Young's modulus decreased. The temperature sensitivity of the Young's modulus of SLM aluminum with columnar grains stretched along the $x$-axis was the greatest. The temperature sensitivity of the Young's modulus of SLM aluminum with columnar grains stretched along the $z$-axis was greater than that of single-crystal aluminum, but less than that of aluminum with equiaxed grains. The correlation between the Young's modulus and temperature was approximately linear.

By observing the atomic snapshots of each stretching stage at different temperatures, we analyzed the evolution of crystalline aluminum during the tensile process. Figure 5 presents snapshots of the different crystalline forms of aluminum at $300 \mathrm{~K}$. Figure 5a,b show that as the strain increased, the FCC structure began to undergo an amorphous transformation, in which the content of amorphous atoms began to increase. This improved the strength to a certain extent, and a small number of BCC atoms appeared. When the strain was 0.14 , stacking faults began to appear inside the crystals, and amorphization was intensified. Then the amorphous atoms agglomerated, as shown in the red circle in Figure 5 c. At this time, the dominant deformation mechanisms of the single crystals were stacking fault formation and amorphization.

Figure $5 \mathrm{~d}$ shows that equiaxed grains underwent dislocation movement and stacking faults began to appear. As the strain increased, the agglomeration of amorphous atoms occurred, and new grain boundaries were produced in red circle 1. Grain boundary migration and torsion were found in red circle 2 in Figure 5e. As the strain continued to increase, the grain boundaries moved continuously and new grains were produced, as shown in the red circle in Figure 5f. At this time, the dominant deformation mechanisms of equiaxed grains were dislocation slip, grain boundary migration, and torsion.

For columnar grains subjected to tension in the $x$-direction, upon increasing the strain from 0.060 to 0.065 , stacking faults began to accumulate. Inside the grains, the stacking faults were parallel to each other, and old dislocations constantly disappeared, and new ones were formed (Figure $5 \mathrm{~g}, \mathrm{~h}$ ). As the strain continued to increase, the grain boundaries underwent migration and torsion, so that the energy of the atomic system was temporarily reduced, as indicated by the red circle 1, and twins were observed in red circle 2 in Figure 5i; this was is basically consistent with a previous description in the literature [19]. The dominant deformation mechanisms of columnar grains were dislocation slip, grain boundary migration, and torsion, which were the same as those of equiaxed grains. Compared with columnar grains and single crystals, equiaxed grains were more prone to dislocation slip.

For columnar grains subjected to tension in the $z$-direction, as the strain increased, an amorphous transformation occurred inside columnar grains, which hindered the movement of stacking faults, as indicated by the red circles in Figure 5j,k. As the strain continued to increase, new grains were formed in red circle 1, and obvious grain boundary migration and torsion were observed in red circle 2 (Figure 5l).

To further analyze the deformation behavior of the different crystal forms of aluminum, we also observed the atomic snapshots at $900 \mathrm{~K}$. Figure $6 \mathrm{a}, \mathrm{b}$ show that the single-crystal lattice distortion was serious, and that the content of amorphous atoms was higher than at the lower temperature. Upon increasing the strain, the content of amorphous atoms increased, and the amorphous atoms became randomly distributed in the crystal. When the strain reached 0.100 , amorphous atomic agglomeration occurred in red circle 1, which formed new grain boundaries, producing new grains inside the crystal. Stacking faults appeared in red circle 2, as indicated in Figure 6c. It can be seen from Figure 6d that the grain boundaries of equiaxed grains were thicker. During stretching, agglomeration occurred at grain boundaries, and the grain boundaries were constantly moving, as shown in the red circle in Figure 6e. When the strain increased to 0.180 (Figure 6f), owing to the movement of grain boundaries, the old grain boundaries disappeared, and the ability to hinder the movement of dislocations was reduced. This led to the generation of stacking faults (red circle 1), and new grains were generated (red circle 2). It can be seen from 
Figure $6 \mathrm{~g}$ that the grain boundaries of the columnar grains were thickened. As the strain increased, the amorphous atoms at the grain boundaries gathered, increasing the thickness of the grain boundaries, as shown in the red circle in Figure $6 \mathrm{~h}$. When the strain reached 0.125 (Figure 6i), grain boundary fracture occurred at red circle 1 , and grain boundary migration and torsion occurred at red circle 2. As seen in Figure 6j,k, as the strain increased, the lattice distortion was intensified, leading to significant amorphous transformation inside the grains. When the strain reached 0.083 (Figure 61), stacking faults formed inside the grains (red circle 1) and amorphous agglomeration occurred at the grain boundary in red circle 2 .
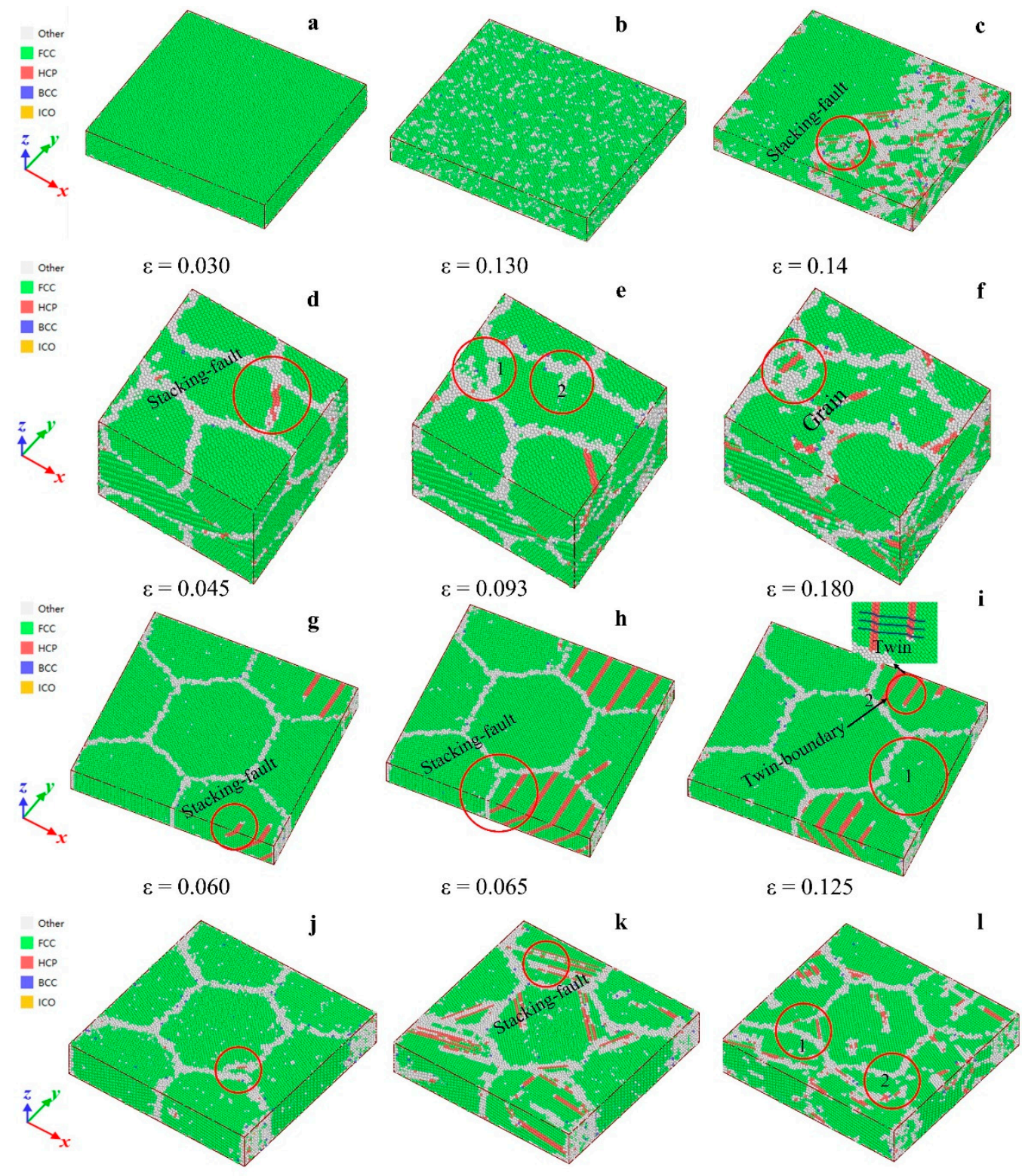

$\varepsilon=0.093$

$\varepsilon=0.100$

$\varepsilon=0.163$

Figure 5. Tensile atomic snapshots of different aluminum crystal forms at $300 \mathrm{~K}$ : (a-c) single crystal, (d-f) equiaxed grain, ( $\mathbf{g}-\mathbf{i})$ columnar grain ( $x$-axis), and (j-1) columnar crystal ( $z$-axis) (white atoms indicate grain boundaries and amorphous structures, and red atoms indicate stacking faults). 

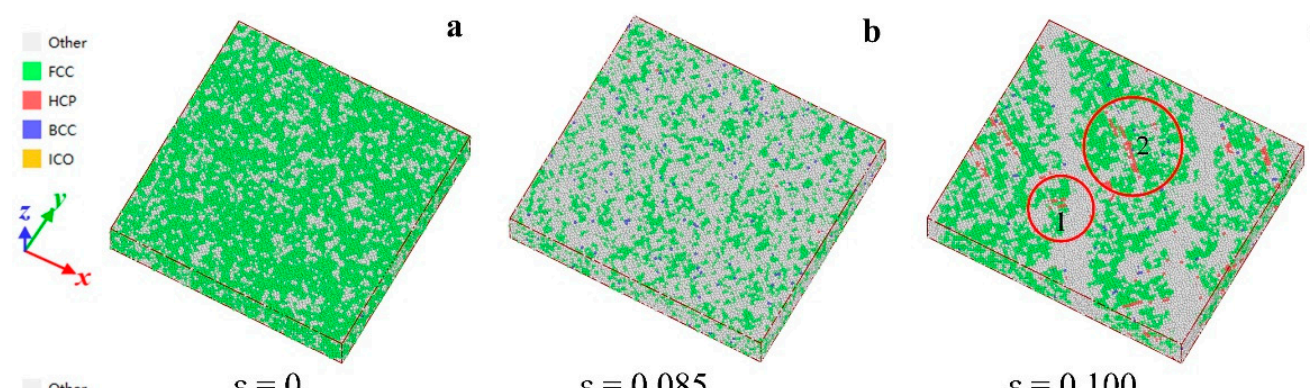

c

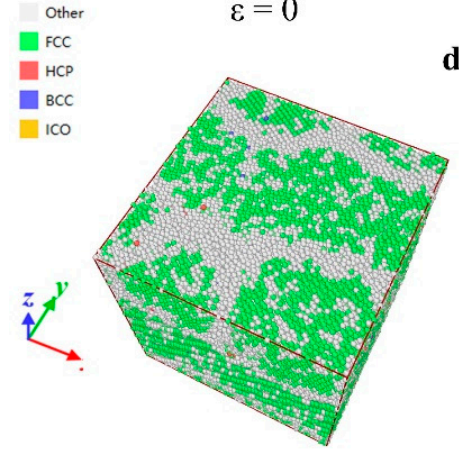

d

$\varepsilon=0.085$

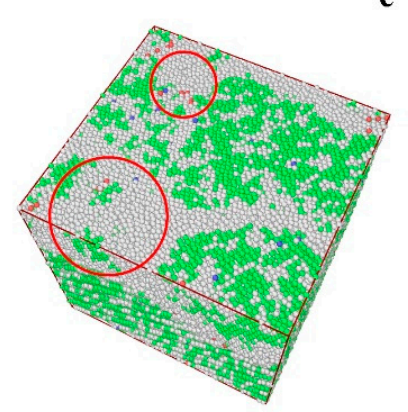

$\varepsilon=0.043$
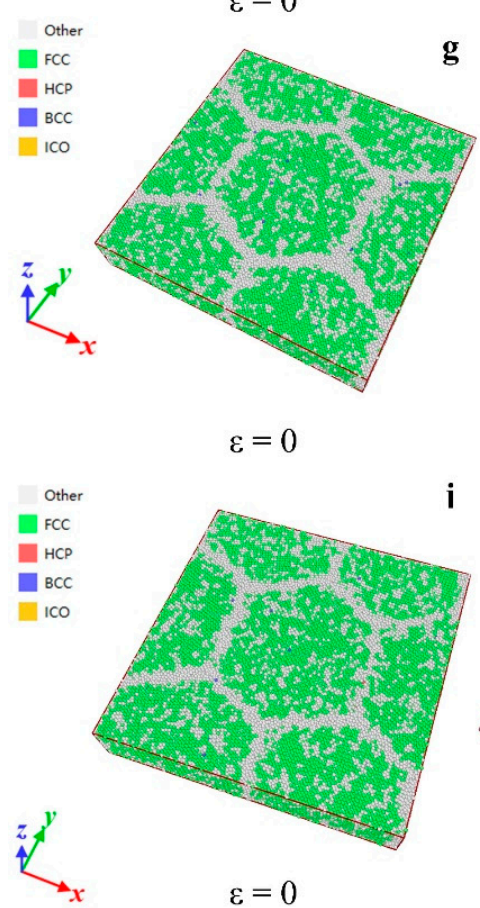

$\varepsilon=0$
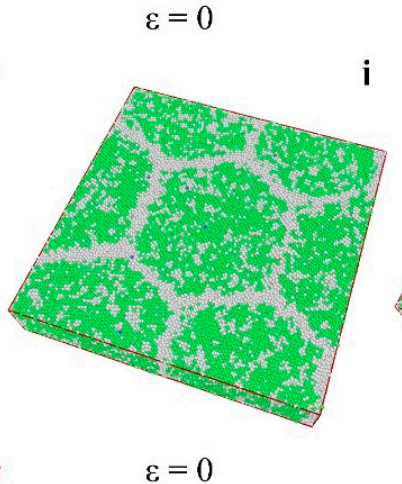

$\varepsilon=0$

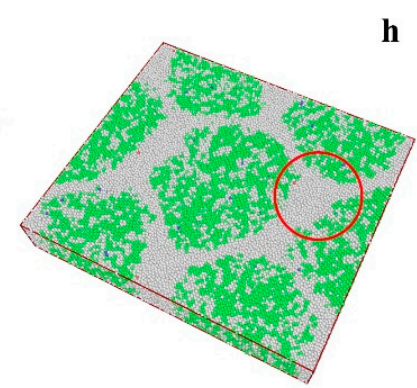

$\varepsilon=0.080$

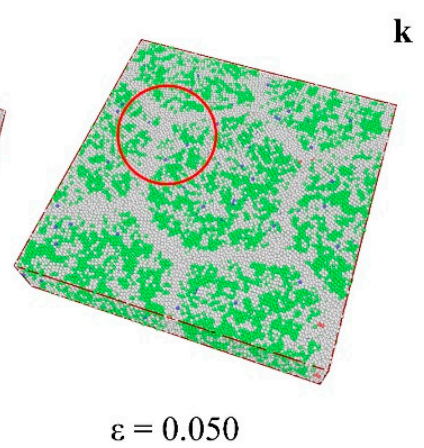

$\mathbf{k}$

h
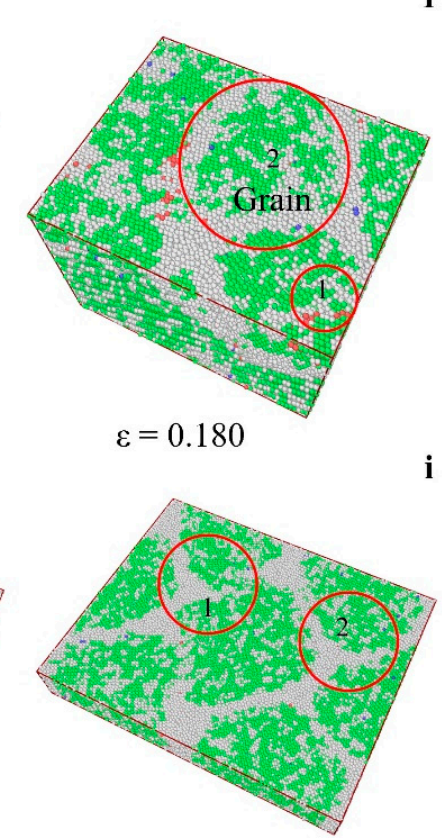

$\varepsilon=0.125$

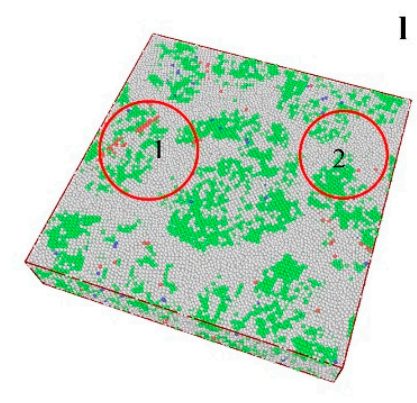

$\varepsilon=0.083$

Figure 6. Tensile atomic snapshots of different crystal forms of aluminum at $900 \mathrm{~K}$ : (a-c) single crystal, (d-f) equiaxed grain, $(\mathbf{g}-\mathbf{i})$ columnar grain ( $x$-axis), and $(\mathbf{j}-\mathbf{1})$ columnar crystal ( $z$-axis).

\subsection{Mechanical Properties of Columnar Grains with Different Orientations}

Rapid cooling during SLM leads to the formation of special microstructures with different grain orientations [11]; therefore, it is necessary to study the influence of different crystal orientations on the mechanical properties. Different rotation angles of the grains around the $z$-axis were studied, and the results are shown in Figure 7.

Figure 7a showed that the Young's modulus was almost independent of the grain orientation, whereas the tensile strength was dependent on the orientation of columnar grains. It can be seen from Figure $7 \mathrm{~b}$, when the grain orientation changed from Group (e) to Group (b), the strength of the material increased from 2.431 GPa to $4.017 \mathrm{GPa}$, which is 
an approximately $65.2 \%$ increase in strength. This indicated that reasonable control of the grain orientation improved the tensile strength of SLM aluminum.
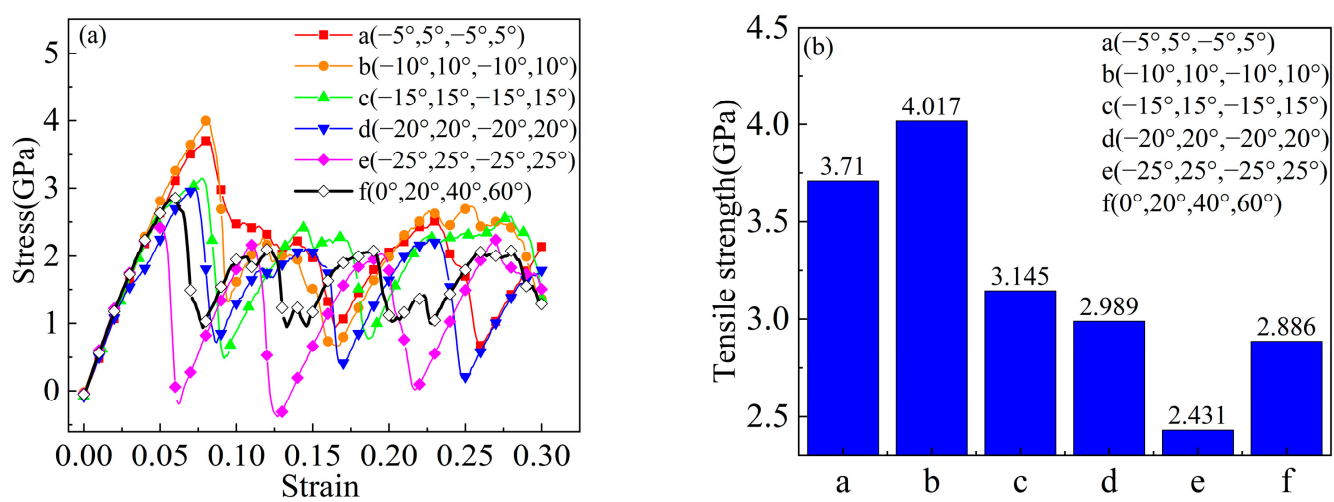

Figure 7. Tensile results of the grains with different rotation angles around the $z$-axis: (a) stress-strain curve and (b) the relationship between tensile strength and rotation angle.

\section{Conclusions}

In this study, the deformation mechanisms of the cellular structures in the selective laser melting (SLM) of aluminum were investigated by performing a series of MD simulations. The effects of crystalline form, temperature, and columnar grain orientation on the mechanical properties of SLM aluminum were investigated. The conclusions of this study can be summarized as follows:

(1) The Young's modulus, yield strength, and tensile strength of SLM aluminum decreased with increasing temperature. The tensile strength of SLM aluminum with columnar grains at different temperatures was lower than that of single-crystal aluminum, but greater than that of aluminum with equiaxed grains.

(2) The tensile strength and Young's modulus both decreased approximately linearly with increasing temperature. The tensile strength of SLM aluminum with columnar grains was more sensitive to temperature than aluminum with equiaxed grains, but less sensitive than single-crystal aluminum. The sensitivity of the Young's modulus of SLM aluminum with columnar grains stretched along the $x$-axis was the greatest, but the sensitivity of the Young's modulus of SLM aluminum with columnar grains stretched along the $z$-axis was greater than that of single-crystal aluminum, but less sensitive than that of aluminum with equiaxed grains.

(3) The deformation mechanisms of equiaxed and columnar grain were dislocation slip, grain boundary migration, and torsion. The deformation mechanisms of single crystals were stacking fault formation and amorphization.

(4) The Young's modulus was almost independent of the grain orientation, but the tensile strength was greatly affected by the orientation of columnar grains. Reasonable control of the grain orientation can improve the tensile strength of SLM aluminum.

Author Contributions: Conceptualization, W.J. and L.W.; methodology, W.J. and Q.Z.; software, Q.Z.; validation W.J., Q.Z. and L.W.; writing—original draft preparation, W.J., Q.Z. and L.W.; writingreview and editing, Q.Z. and W.J.; funding acquisition, W.J. All authors have read and agreed to the published version of the manuscript.

Funding: This work was supported by the National Natural Science Foundation of China under Grant No. 12062016.

Institutional Review Board Statement: Not applicable.

Informed Consent Statement: Not applicable.

Acknowledgments: W.G.J. would appreciate the supported by the National Natural Science Foundation of China under Grant No. 12062016. 
Conflicts of Interest: The authors declare no conflict of interest.

\section{References}

1. Bandyopadhyay, A.; Traxel, K.D. Invited review article: Metal-additive manufacturing-Modeling strategies for applicationoptimized designs. Addit. Manuf. 2018, 22, 758-774. [CrossRef]

2. Guo, N.; Leu, M.C. Additive manufacturing: Technology, applications and research needs. Front. Mech. Eng. 2013, 8, 215-243. [CrossRef]

3. Tofail, S.A.M.; Koumoulos, E.P.; Bandyopadhyay, A.; Bose, S.; O’Donoghue, L.; Charitidis, C. Additive manufacturing: Scientific and technological challenges, market uptake and opportunities. Mater. Today 2018, 21, 22-37. [CrossRef]

4. Zaretsky, E.; Stern, A.; Frage, N. Dynamic response of AlSi10Mg alloy fabricated by selective laser melting. Mater. Sci. Eng. A 2017, 688, 375-380. [CrossRef]

5. Larrosa, N.O.; Wang, W.; Read, N.; Loretto, M.H.; Evans, C.; Carr, J.; Tradowsky, U.; Attallah, M.M.; Withers, P.J. Linking microstructure and processing defects to mechanical properties of selectively laser melted AlSi10Mg alloy. Theor. Appl. Fract. Mec. 2018, 98, 123-133. [CrossRef]

6. Li, W.; Li, S.; Liu, J.; Zhang, A.; Zhou, Y.; Wei, Q.; Yan, C.; Shi, Y. Effect of heat treatment on AlSi10Mg alloy fabricated by selective laser melting: Microstructure evolution, mechanical properties and fracture mechanism. Mater. Sci. Eng. A 2016, 663, 116-125. [CrossRef]

7. Takata, N.; Liu, M.; Kodaira, H.; Suzuki, A.; Kobashi, M. Anomalous strengthening by supersaturated solid solutions of selectively laser melted Al-Si-based alloys. Addit. Manuf. 2020, 33, 101152. [CrossRef]

8. Takata, N.; Kodaira, H.; Sekizawa, K.; Suzuki, A.; Kobashi, M. Change in microstructure of selectively laser melted AlSi10Mg alloy with heat treatments. Mater. Sci. Eng. A 2017, 704, 218-228. [CrossRef]

9. Thijs, L.; Kempen, K.; Kruth, J.P.; Humbeeck, J.V. Fine-structured aluminium products with controllable texture by selective laser melting of pre-alloyed AlSi10Mg powder. Acta Mater. 2013, 61, 1809-1819. [CrossRef]

10. Ben, D.D.; Ma, Y.R.; Yang, H.J.; Meng, L.X.; Shao, X.H.; Liu, H.Q.; Wang, S.G.; Duan, Q.Q.; Zhang, Z.F. Heterogeneous microstructure and voids dependence of tensile deformation in a selective laser melted AlSi10Mg alloy. Mater. Sci. Eng. A 2020, 798, 140109. [CrossRef]

11. Chen, B.; Moon, S.K.; Yao, X.; Bi, G.; Shen, J.; Umeda, J.; Kondoh, K. Strength and strain hardening of a selective laser melted AlSi10Mg alloy. Scripta Mater. 2017, 141, 45-49. [CrossRef]

12. Kurian, S.; Mirzaeifar, R. Deformation mechanisms of the subgranular cellular structures in selective laser melted 316L stainless steel. Mech. Mater. 2020, 148, 103478. [CrossRef]

13. Mei, A.B.; Kindlund, H.; Broitman, E.; Hultman, L.; Petrov, I.; Greene, J.E.; Sangiovanni, D.G. Adaptive hard and tough mechanical response in single-crystal B1 VNx ceramics via control of anion vacancies. Acta Mater. 2020, 192, 78-88. [CrossRef]

14. Ghaffarian, H.; Taheri, A.K.; Kang, K.; Ryu, S. Molecular dynamics simulation study of the effect of temperature and grain size on the deformation behavior of polycrystalline cementite. Scripta Mater. 2015, 95, 23-26. [CrossRef]

15. Husain, A.; La, P.; Yue, H.; Sheng, J. Influence of temperature on mechanical properties of nanocrystalline 316L stainless steel investigated via molecular dynamics simulations. Materials 2020, 13, 2803. [CrossRef]

16. Zepeda-Ruiz, L.A.; Stukowski, A.; Oppelstrup, T.; Bertin, N.; Barton, N.R.; Freitas, R.; Bulatov, V.V. Atomistic insights into metal hardening. Nat. Mater. 2020, 20, 315-320. [CrossRef]

17. Branco, D.D.C.; Vasconcelos, L.; An, L.; Zhao, K.; Cheng, G.J. Ultrastrong pure aluminum structure with gradient via selective pulsed laser melting: Computation framework and experiments. J. Mech. Phys. Solids 2021, 151, 104391. [CrossRef]

18. Qi, Y.; Krajewski, P.E. Molecular dynamics simulations of grain boundary sliding: The effect of stress and boundary misorientation. Acta Mater. 2007, 55, 1555-1563. [CrossRef]

19. Yamakov, V.; Wolf, D.; Phillpot, S.; Mukherjee, A.K.; Gleiter, H. Dislocation processes in the deformation of nanocrystalline aluminium by molecular-dynamics simulation. Nature Mater. 2002, 1, 45-49. [CrossRef]

20. Li, S.F.; Wang, G. Introduction to Micromechanics and Nanomechanics; World Scientific Publishing Company: Singapore, 2008.

21. Zhu, H.; Chen, J.; Chen, H.Q.; Fang, L.; Sun, K. Loading direction-dependent mechanical properties of columnar polycrystal: A molecular dynamics study. J. Mater. Eng. Perform. 2021, 30, 1970-1980. [CrossRef]

22. Mishin, Y.; Farkas, D.; Mehl, M.J.; Papaconstantopoulos, D.A. Interatomic potentials for monoatomic metals from experimental data and ab initio calculations. Phys. Rev. B 1999, 59, 3393-3407. [CrossRef]

23. Plimpton, S. Fast parallel algorithms for short-range molecular dynamics. J. Comput. Phy. 1995, 117, 1-19. [CrossRef]

24. Li, Y.C.; Jiang, W.G.; Zhou, Y. Molecular dynamics simulation of the tensile mechanical response of single crystal/polycrystalline nickel, Rare. Metal. Mat. Eng. 2020, 49, 2372-2379.

25. Wen, Y.H.; Zhu, Z.Z.; Zhu, R.Z. Molecular dynamics study of the mechanical behavior of nickel nanowire: Strain rate effects. Comp. Mater. Sci. 2008, 41, 553-560. [CrossRef]

26. Evans, D.J.; Holian, B.L. The Nose-Hoover thermostat. J. Chem. Phys. 1985, 83, 4069-4074. [CrossRef]

27. Stukowski, A. Visualization and analysis of atomistic simulation data with OVITO-the open visualization tool. Model. Simul. Mater. Sci. Eng. 2010, 18, 2154-2162. [CrossRef]

28. Hirel, P. Atomsk: A tool for manipulating and converting atomic data files. Comput. Phys. Commun. 2015, 197, 212-219. [CrossRef]

29. Finney, J.L. A procedure for the construction of voronoi polyhedral. J. Comput. Phys. 1979, 32, 137-143. [CrossRef] 
30. Bertolino, G.; Ruda, M.; Pasianot, R.; Farkas, D. Atomistic simulation of the tension/compression response of textured nanocrystalline HCP Zr. Comp. Mater. Sci. 2017, 130, 172-182. [CrossRef]

31. Rajput, A.; Paul, S.K. Cyclic plastic deformation response of nanocrystalline BCC iron. Met. Mater. Int. 2021, $27,825-837$. [CrossRef]

32. Zhang, L.; Shibuta, Y.; Huang, X.; Lu, C.; Liu, M. Grain boundary induced deformation mechanisms in nanocrystalline Al by molecular dynamics simulation: From interatomic potential perspective. Comp. Mater. Sci. 2019, 156, 421-433. [CrossRef]

33. Suk, M.E. Effect of the nanotube radius and the volume fraction on the mechanical properties of carbon nanotube-reinforced aluminum metal matrix composites. Molecules 2021, 26, 3947. [CrossRef] [PubMed]

34. Haque, M.A.; Saif, M.T.A. Mechanical behavior of 30-50 nm thick aluminum films under uniaxial tension. Scripta Mater. 2002, 47, 863-867. [CrossRef]

35. Matli, P.R.; Ubaid, F.; Shakoor, R.A.; Parande, G.; Gupta, M. Improved properties of $\mathrm{Al}-\mathrm{Si}_{3} \mathrm{~N}_{4}$ nanocomposites fabricated through a microwave sintering and hot extrusion process. RSC Adv. 2017, 7, 34401-34410. [CrossRef] 